\title{
La cooperación internacional descentralizada en Colombia: un análisis institucionalista sobre el departamento de Cundinamarca*
}

\author{
Denisse Grandas Estepa** \\ Juan Pablo Prado Lallande ${ }^{* * *}$
}

\section{RESUMEN}

La cooperación internacional descentralizada es una modalidad de colaboración externa que complementa capacidades locales a efecto de incentivar el desarrollo en los territorios. Desde la teoría institucionalista de las Relaciones
Internacionales, la cooperación internacional, en general, y la descentralizada, en particular, pueden generar importantes insumos a favor del fortalecimiento de procesos y recursos en los territorios, en caso de que dicha actividad cuente con el suficiente respaldo político y de un adecuado andamiaje jurídico e insti-

* Este artículo es un resultado del proyecto de investigación "Estudio comparativo de las dinámicas institucionales de la cooperación descentralizada en Colombia y México. Los casos de Bogotá, Cartagena, Ciudad de México y Puebla (2009-2013)". La investigación hace parte del Convenio de cooperación interinstitucional entre la Universidad Jorge Tadeo Lozano y la Benemérita Universidad Autónoma de Puebla, México. Un borrador preliminar de este artículo se presentó a través de una ponencia, en el viI Congreso de Relaciones Internacionales del Instituto de Relaciones Internacionales de la Universidad Nacional de La Plata, Argentina, en noviembre de 2014.

** Magíster en Desarrollo y Ayuda Internacional. Docente del Departamento de Ciencia Política y Relaciones Internacionales, Facultad de Ciencias Sociales, Universidad Jorge Tadeo Lozano. Bogotá (Colombia) [denisse.grandas@utadeo.edu.co].

*** Doctor en Relaciones Internacionales y Unión Europea. Docente-investigador de la Academia de Relaciones Internacionales, Facultad de Derecho y Ciencias Sociales, Benemérita Universidad Autónoma de Puebla (México) [juanp.prado@correo.buap.mx].

Recibido: 20 de junio de 2016 / Modificado: 22 de agosto de 2016 / Aceptado: 10 de septiembre de 2016

Para citar este artículo

Grandas Estepa, D. y Prado Lallande, J. P. (2017). La cooperación internacional descentralizada en Colombia. Un análisis institucionalista sobre el departamento de Cundinamarca. OAsIs, 25, 159-186.

DOI: https://doi.org/10.18601/16577558.n25.10 
tucional. A la luz de tales planteamientos, el artículo tiene como principal propósito analizar los antecedentes, la evolución y el estado de la institucionalización de la cooperación descentralizada en el departamento de Cundinamarca, Colombia, a fin de identificar sus potencialidades y elementos de oportunidad más representativos. Como conclusión general se sostiene que, dados los resultados de este estudio, el citado departamento requiere continuar avanzando hacia mejores y más eficaces esquemas de institucionalización de su cooperación internacional, con miras a hacer de esta actividad un instrumento complementario a las capacidades locales con mayor habilidad para impactar de forma positiva en el desarrollo a favor de la población de dicho territorio.

Palabras clave: cooperación internacional descentralizada, Colombia, Cundinamarca, institucionalización.

\section{Decentralized international cooperation in Colombia. An institutionalist analysis of the Department of Cundinamarca}

\section{ABSTRACT}

Decentralized international cooperation is a modality that seeks to promote foreign collaboration for local development in a given country. It aims to be complementary to local capabilities in cases when there are internal limitations. From IR institutionalist theory, international cooperation, in general, and descentralized cooperation, in particular, have the potential to promote processes and to find resources if they have a comprehensive legal and institutional set of tools to make it possible. From this perspective, the main purpose of this article is to analyze the history, evolution and state of the institutionalization process, through a case study of decentralized cooperation in the Cundinamarca Department of Colombia. The goal of this research is to identify the achievements, as well as its core challenges. As a general conclusion, we argue that Cundinamarca needs to continue developing better and more effective schemes of institutionalization of its international cooperation, in order to foster more effective outputs within that territory.

Key words: Descentralized international cooperation, Colombia, Cundinamarca, institutionalization.

\section{INTRODUCCIÓN}

En ańos recientes, la cooperación internacional para el desarrollo (CID) muestra múltiples transformaciones en su actuar, entre otras razones debido al creciente activismo de nuevos actores como los países emergentes, los gobiernos subnacionales, las organizaciones de la sociedad civil y las empresas. Esto incentiva la configuración de nuevas modalidades de colaboración como la cooperación Sur-Sur (css), la triangular, la descentralizada, entre otras. Esta circunstancia ocasiona que la CID, en sus diversas facetas, registre un dinámico 
proceso de renovación de sus normativas, instituciones de gestión y procesos operativos.

En este dinámico escenario, como ocurre en otras latitudes del planeta, los gobiernos subnacionales en Colombia se enfrentan al reto de perfeccionar la planeación, la organización institucional y la acción estratégica de la cooperación internacional que los vincula con el exterior. Lo anterior es relevante, dado que frente a requerimientos territoriales que no pueden ser abordados en su completa dimensión mediante capacidades propias, la CID se erige como un instrumento complementario a tales activos locales. De igual manera, en caso de contar con expertisse y buenas prácticas en determinado asunto de interés público, la CID facilita procesos para compartir tales capacidades con terceros países. En todo caso, e independientemente de sus vertientes y modalidades, la CID, en caso de contar con adecuado respaldo político, puede generar importantes beneficios a favor del reforzamiento de procesos y recursos del orden local, siempre y cuando el territorio en cuestión y sus respectivas autoridades cuenten con un adecuado proceso de planificación jurídico e institucional a nivel nacional y local, siendo este el argumento central del presente artículo.

De forma concreta, para el caso del departamento de Cundinamarca, Colombia, la ruta por una apuesta departamental a favor de mejores estadios de desarrollo conlleva un ejercicio interno de planeación, diálogo y construcción de acuerdos y estrategias acordes con los retos que enfrenta tal demarcación. En este sentido, se considera que la cooperación internacional -como instrumento que refuerza, no sustituye, capacidades locales que se instrumentan en dicho departamento-, si bien registra avances, también muestra rasgos de desarticulación, así como déficit en la coordinación y apropiación de sus actividades y procesos. Lo anterior se explica en buena medida por los incipientes procesos de institucionalización de la CID en dicha actividad por parte del gobierno local.

A la luz de estos planteamientos generales, este artículo tiene como eje rector analizar los antecedentes, la evolución y el estado actual de la institucionalización de la cooperación descentralizada (CD) en el departamento de Cundinamarca, Colombia, con el fin de identificar sus potencialidades y elementos de oportunidad más representativos. Como se argumenta en el texto, tal proceso requiere de la instrumentación de una estrategia de internacionalización más adecuada, en línea con los preceptos del institucionalismo de las relaciones internacionales, aunque a la par de ello se requiere también de la voluntad política por parte de las autoridades para conseguir tal aspiración.

Para atender a tal propósito, el artículo se divide en cinco secciones. Tras esta Introducción, el primer apartado se compone de una contextualización general de los cambios y las transformaciones del sistema de CID, haciendo énfasis en la necesidad de repensar la colaboración externa y sus procesos institucionales desde los entes territoriales, tomando como referente Colombia. Esto se hace bajo los fundamentos teóricos propios del liberalismo institucional de las Relaciones Internacionales.

Con base en ello, en la segunda sección se estudian las tendencias de los últimos años 
respecto a la $\mathrm{CD}$, haciendo énfasis en la experiencia de los municipios colombianos.

La tercera parte del artículo analiza la CD en el departamento de Cundinamarca. Para ello se recurre, como principal eje de análisis, a la evolución y el estado de institucionalización de dicha actividad en la demarcación citada.

Como principal conclusión se sostiene que en el departamento de Cundinamarca, tal y como ocurre en otros territorios colombianos, e incluso en otros países, más allá de los avances registrados, esta circunscripción encara el reto de fortalecer los procesos de institucionalización de la cooperación internacional que se practica en dicha localidad. Se señala también que atender a dicho requerimiento amerita de una renovada voluntad política por parte del Gobierno en turno para reforzar la institucionalidad de su CD. Esto, a efecto de que se cuente con una estructura legal, institucional y programática capaz de incidir con mayor impacto en los procesos de desarrollo local mediante el respaldo de ejercicios de cooperación internacional.

\section{EL CONTEXTO ACTUAL DE LA COOPERACIÓN INTERNACIONAL PARA EL DESARROLLO. VERTIGINOSOS CAMBIOS A FAVOR DE SU RENOVADA INSTITUCIONALIDAD}

El panorama actual por el que atraviesa la CID se explica por diversos factores relacionados con las transformaciones en las visiones del desarrollo, la recomposición de la geopolítica mundial, los liderazgos políticos en determinados países, la cambiante dinámica de la economía internacional, así como por los cambios institucionales de la organización internacional global, regional, nacional y local. Esto, en su conjunto, genera un interesante escenario en el que de forma cada vez más visible los territorios de los países ejercen un creciente papel como entes activos de las relaciones internacionales y de la propia CID. Lo anterior se explica, entre otros, por la intersección de los siguientes factores:

En primer lugar, debido a la creciente internacionalización de los gobiernos descentralizados y a su papel en el escenario exterior. Tal fenómeno es a su vez fruto de los procesos de globalización y reconfiguración de espacios sociales, económicos y políticos, que se suman a renovados procesos de modernización de la gestión y las políticas públicas en diversas administraciones locales. Ello tiene sentido a la luz de la descentralización administrativa y fiscal que se vive en diversas localidades de distintos países, lo cual, junto con mayores espacios para la vida democrática en los territorios, y el uso exponencial de redes y medios de comunicación el línea, genera un entorno adecuado para una creciente vinculación de los territorios con el contexto internacional. La conjunción de lo anterior decanta en el concepto de "poder glocal", entendido como aquel escenario para responder a las múltiples demandas sociales territoriales, forjadas a partir de lógicas globales (Martínez y Sanahuja, 2009).

Un segundo factor está relacionado con la crisis económica y financiera internacional, la cual, junto a criterios de reordenamiento de sus prioridades geopolíticas, afecta el otorgamiento de colaboración externa "tradicional" (Norte-Sur) por parte de donantes como España, Estados Unidos, la Unión Europea, entre 
otros, a países en desarrollo. Esta situación se manifiesta mediante recortes presupuestarios $y$, en algunos casos, cambios de prioridades y criterios de asignación unilaterales en las políticas de ayudas conferidas por tales proveedores.

La tabla 1 evidencia la variación de recursos de Asistencia Oficial para el Desarrollo (AOD) a diversos países de América Latina y el Caribe durante los años 2012 y 2014, contabilizados por la Organización para la Cooperación y el Desarrollo Económico (ocDE).

Esta misma dinámica viene acompaña del debate sobre el creciente activismo internacional de los países de renta media (PRM), los cuales, desde la visión de algunos donantes tradicionales, no deben ser receptores prioritarios de estos apoyos. Ello, como lo explica Alonso (2007), en razón del impreciso argumento respecto a que la cooperación debe ir orientada de forma exclusiva hacia países con mayores índices de pobreza, lo que implica una mayor atención a regiones altamente empobrecidas como África subsahariana, dejando por tanto en un segundo plano a América Latina y el Caribe.

Pese a esta discusión, el país de referencia se muestra como uno de los principales receptores de AOD en América Latina y el Caribe. Esto se explica en buena medida porque este tipo de apoyo foráneo no responde en exclusiva a criterios de elegibilidad tradicionales

TABLA 1. DIEZ PRINCIPALES RECEPTORES DE AOD EN AMÉRICA LATINA Y EL CARIBE (MILLONES DE DÓLARES NETOS DE AOD)

\begin{tabular}{|c|c|c|c|c|c|}
\hline & 2012 & 2013 & 2014 & $\begin{array}{l}\text { Promedio de } \\
\text { los } 3 \text { años }\end{array}$ & $\%$ \\
\hline 1 Haití & 1272 & 1152 & 1083 & 1169 & 12 \\
\hline 2 Brasil & 1281 & 1145 & 912 & 1112 & 11 \\
\hline 3 Colombia & 763 & 854 & 1221 & 946 & 9 \\
\hline 4 Bolivia & 658 & 700 & 672 & 677 & 7 \\
\hline 5 Honduras & 568 & 627 & 604 & 600 & 6 \\
\hline 5 México & 417 & 561 & 807 & 595 & 6 \\
\hline 7 Nicaragua & 532 & 497 & 430 & 486 & 5 \\
\hline 9 Guatemala & 303 & 495 & 277 & 358 & 4 \\
\hline 8 Perú & 385 & 360 & 325 & 357 & 4 \\
\hline $\begin{array}{l}\text { República } \\
\text { Dominicana }\end{array}$ & 261 & 147 & 167 & 192 & 2 \\
\hline $\begin{array}{l}\text { Otros } \\
\text { receptores }\end{array}$ & 3625 & 3694 & 3451 & 3590 & 35 \\
\hline Total receptores de AOD & 10065 & 10232 & 9949 & 10082 & 100 \\
\hline
\end{tabular}

Fuente: OCDE (2016). 
(en términos de pobreza y subdesarrollo), definidos por el Comité de Ayuda al Desarrollo (CAD) de la OCDE. Lo anterior se evidencia en la reacción de la comunidad internacional frente al conflicto armado en Colombia, y a su posible término, lo cual se espera abra una nueva etapa de desarrollo en este Estado sudamericano. Ello, sumado a la situación de los derechos humanos, el desplazamiento forzado, los índices de inequidad, a la pobreza misma, a inercias como receptor relevante desde hace décadas, así como a la relevancia política, económica y geoestratégica en términos de seguridad, ocasiona que Colombia sea un importante receptor de este tipo de ayuda internacional.

Sumado a esto, el esquema tradicional de cooperación Norte-Sur registra modificaciones debido a que los PRM han roto el monopolio de este esquema tradicional para convertirse en activos proveedores de cooperación Sur-Sur (Olivié y Domínguez, 2013; Ayllón, 2016). Así por ejemplo, Brasil es uno de los grandes actores de la css, que pretende contribuir, entre otras cosas, a la transferencia de soluciones innovadoras para el desarrollo en diversos sectores, e incluso, impulsando nuevas modalidades de cooperación y priorizando las relaciones del país con otros países del sur (Ayllón y Costa, 2010).

Colombia, en su condición de PRM, y como una herramienta de su política exterior, asume este escenario como una oportunidad para avanzar en una estrategia de inserción internacional desde el Gobierno nacional para intentar posicionarse de mejor manera en la región como proveedor de css. Una clara manifestación (con sus logros y respectivos costos políticos) de esto fue, por ejemplo, el activo papel que Bogotá asumió en los espacios políticos y de debate de la agenda de eficacia de la ayuda y, en particular, en la evaluación voluntaria de la implementación de la Declaración de París en el año 2010.

De igual forma, y ahondando en la experiencia del país, la creación en 2011 de la Agencia Presidencial de Cooperación Internacional de Colombia (APC-Colombia) y la Hoja de Ruta de la Cooperación Internacional (2015-2018), que plantea los lineamientos prioritarios de la agenda de cooperación internacional que ofrece y recibe el país, puede percibirse como una renovada voluntad política, al más alto nivel, para reposicionarlo en el plano de la cooperación, en línea con las prioridades de su política exterior.

Un tercer aspecto tiene que ver con la promoción de nuevos esquemas y modalidades de colaboración internacional que pretenden conseguir mayores niveles de horizontalidad e inclusión entre sus diversos participantes. La Css y la triangular son los ejemplos más representativos de ello, mientras que la de carácter descentralizado enfrenta el reto de conectar al territorio con otros actores extranacionales, mediante mecanismos que no repliquen esquemas verticalistas y excluyentes. Estas fórmulas de colaboración promueven el intercambio de conocimientos y buenas prácticas, el desarrollo de capacidades y la asistencia técnica mediante esquemas sustentados en la corresponsabilidad, aunque en diversos casos tales aspiraciones son complejas de conseguir.

Este renovado dinamismo que experimenta la CID, junto con la difusión de información y el desarrollo de las telecomunicaciones 
en tiempo real permite que junto con los Estados y las organizaciones multilaterales, los gobiernos territoriales, las organizaciones de la sociedad civil, las empresas, las universidades, las iglesias, entre otras, se involucren de manera cada vez más decidida en múltiples ejercicios de cooperación internacional.

Finalmente, y como cuarto punto, las transformaciones en el mapa del desarrollo generan nuevas condiciones, digamos "estructurales", en el sistema de CID. En este sentido, el ocaso en 2015 de la era de los Objetivos de Desarrollo del Milenio como escenario prioritario de las acciones de la CID, y la subsiguiente entrada en vigor de la Agenda 2030 de Desarrollo Sostenible (más adaptativa a las necesidades de desarrollo en Latinoamérica y, por ende, de sus entidades descentralizadas), propician un contexto favorable en términos de mayor involucramiento de autoridades y de la sociedad nacional y subnacional en materia de desarrollo y cooperación internacional.

Por último, y como un aspecto exclusivo respecto a Colombia, como se señaló previamente, el país enfrenta un proceso a favor de la paz y reconciliación nacional. Por ello, temas como la construcción de paz ocupan -de manera prioritaria en la agenda nacional- el centro en la justificación y necesidad de continuar celebrando acuerdos y acciones de CID. Esto, a su vez, exige al Gobierno nacional y a los territoriales una mejor planeación, gestión, articulación, seguimiento, evaluación y, a la postre, institucionalización de la cooperación internacional en este país a nivel nacional y subnacional.

A ese respecto, la institucionalización de la cooperación internacional permite ordenar, coordinar, estructurar, sistematizar, conducir y planear las actividades de colaboración en pro de la coherencia, la complementariedad, la armonización y la apropiación de los programas o proyectos instrumentados al amparo de su ejercicio. Esto, ya sea a nivel global, nacional o local, con miras a propiciar con mayor margen de oportunidad resultados predictibles a favor del desarrollo.

De ahí que desde la teoría de las Relaciones Internacionales de perfil liberal y, concretamente, en su vertiente institucionalista, se argumenta que la estructura y el diseño de instituciones colectivas y organizaciones nacionales, subnacionales e internacionales juegan un rol trascendental en las acciones de cooperación internacional (Jackson y Sorensen, 2010).

En ese sentido, para esta vertiente teórica las instituciones nacionales (oficinas, agencias de cooperación, etc.) o internacionales (organismos multilaterales, mecanismos de colaboración o integración, etc.) facilitan el ejercicio de la cooperación internacional (Prado, 2013). Lo anterior dado a que al establecer reglas de coordinación tanto dentro de los países como entre gobiernos nacionales, locales y otros actores internacionales, los practicantes de la cooperación internacional se encuentran en mayor capacidad de cumplir con los objetivos trazados.

$\mathrm{El}$ argumento central de los especialistas en Relaciones Internacionales dedicados a este tema consiste en que una adecuada institucionalización de la cooperación internacional reduce de manera significativa los efectos de la anarquía en el sistema internacional o la discrecionalidad, corrupción y costes de tran- 
sacción a escala nacional o local en las acciones inherentes a su ejercicio. Lo anterior gracias al establecimiento de un andamiaje normativo y procedimental a favor de la interacción y acción conjunta entre determinados participantes en un ámbito específico de interés común. Ello, debido a que tales normas e instancias restringen y conducen el comportamiento de autoridades en lo particular y gobiernos en lo general a favor de propósitos colectivos y, por ende, reducen la discrecionalidad de su actuar.

De esta forma, las instituciones contribuyen a reducir la desconfianza entre los cooperantes, promueven la continuidad en la interacción entre sí y, por ende, generan sensación de estabilidad y certidumbre en sus respectivas relaciones y acciones conjuntas. Junto con lo anterior, las instituciones estimulan esquemas de sinergia, compromiso y mayor transparencia a favor de la generación de beneficios compartidos y ventajas mutuas entre los participantes y beneficiarios (Jackson y Sorensen, 2010).

De ahí que desde este enfoque, la clave de un adecuado ejercicio de cooperación internacional reside en la estructura, el diseño y la manera de funcionar de las instancias político-administrativas responsables de la instrumentación de dicha actividad (Karns y Mingts, 2010).

Desde esta óptica, el funcionamiento y la operatividad de las instancias -y en este caso, aquellas del orden nacional o subnacional dedicadas a la gestión y conducción de la cooperación internacional-se sustentan en la aplicación de reglas o normas. El fin de estas consiste en promover procesos institucionalizados de sus actividades, en el sentido de que las acciones y los resultados que de estas emanen sean durables y predeterminados. En otras palabras, ello significa que las normas y sus respectivas instituciones deben ser capaces de conducir el comportamiento del gobierno ejecutor y, por ende, moldear las expectativas generadas en el ámbito de acción correspondiente (Jackson y Sorensen, 2010).

La necesidad de establecer tales normas e instituciones se debe a que el ejercicio de la cooperación internacional no es una labor sencilla de realizar, debido a que lograr la convergencia de objetivos y estrategias para conseguirlos entre dos o más actores constituye un reto complejo de acordar y abordar (Sterling-Folker, 2006).

En resumen, esta matriz teórica descansa en el papel de las instituciones ya sean del orden nacional o internacional, cuyo fin esencial es conducir el comportamiento de los responsables de poner en marcha ejercicios de cooperación internacional (Kay, 2006), y con ello establecer procesos institucionalizados a efecto de que las acciones y los resultados sean predecibles, durables y a la postre eficaces (Prado, 2014).

La manera de realizar ejercicios concretos en pro de la institucionalización de la cooperación internacional amerita una serie de aspectos y procedimientos afines a los preceptos aquí esgrimidos, cuyos elementos más representativos y adaptativos respecto a instituciones nacionales y territoriales que practican cooperación internacional son los siguientes:

a) Legislación ad hoc, coherente con el contexto internacional, nacional y territorial; b) definición de objetivos explícitos, sectores, 
regiones y países prioritarios; c) institución permanente y estable que gestione la cooperación; d) sistema de control y registro de los convenios, programas y proyectos de cooperación internacional; e) recursos permanentes y contabilizados destinados a la colaboración externa; f) personal capacitado y especializado en el ámbito de la CID; g) procesos de evaluación sistemática de los resultados de las actividades realizadas; h) mecanismos de rendición de cuentas, con miras a -en caso necesario- reconducir decisiones y acciones a favor de mejores estándares de calidad; i) instrumentos a favor de la coordinación con respecto a los objetivos globales de desarrollo, las políticas nacionales y de otros territorios nacionales de cooperación internacional; j) todo ello en consonancia con los objetivos de desarrollo y de política exterior del país en cuestión (Prado, 2011).

Las consideraciones descritas dedicadas a la interacción entre normas e institucionalización de procesos abren paso al concepto de la política pública de la CID, concepción que consiste en la aplicación de normas por parte de la institución nacional o local correspondiente, mismas que tienen como propósito esencial orientar y definir la instrumentación de la CID organizada en determinado espacio geográfico con base en objetivos definidos y alineados respecto a instancias superiores. Dicho proceso debe realizarse mediante la planeación, operación y seguimiento sistematizado de sus acciones y resultados, conducidos por determinado Gobierno y personal administrativo, y con el concurso de la sociedad, con miras a contribuir al desarrollo del país y de sus territorios.

\section{LA DINÁMICA DE LA COOPERACIÓN DESCENTRALIZADA: \\ EL CASO DEL DEPARTAMENTO DE CUNDINAMARCA}

El concepto de CD puede ser entendido desde dos enfoques: para algunos, hace referencia a la cooperación que se realiza desde las organizaciones de la sociedad civil; es decir, aquellas acciones de esta naturaleza de perfil no oficiales. Para otros, la CD es la actividad que se enmarca en las relaciones entre gobiernos subnacionales adscritos a distintos países de forma directa o a través de la sociedad civil o diversos actores del desarrollo.

Para APC-Colombia la CD se entiende como:

El conjunto de las acciones de cooperación internacional que realizan o promueven los gobiernos locales y regionales. Se caracteriza por ser un modelo dinámico, con visión de mediano y largo plazo, en donde se ve implicada la responsabilidad política y la legitimidad, con el propósito de potencializar el desarrollo en el territorio, con la participación directa de los grupos de población interesados (APCColombia, 2013, p. 2).

Pese a las diferentes concepciones a este respecto existe en la actualidad un elevado consenso en que la $\mathrm{CD}$ puede ser entendida como "el conjunto de iniciativas de cooperación oficial al desarrollo que, bajo el liderazgo de autoridades locales, procura estimular las capacidades de los actores de base territorial y fomentar un desarrollo más participativo" (Del Huerto, 2005, p. 53). 
Las diferentes prácticas de $\mathrm{CD}$ en su conjunto se clasifican de diversas maneras. De acuerdo con Gutiérrez (2006), existen dos tipos de vínculos de CD: los institucionalizados y los informales. Los institucionalizados (acorde con la fundamentación teórica de este artículo) se caracterizan por una mayor formalidad de relaciones bilaterales a través de los hermanamientos, asociaciones entre gobiernos subnacionales y su participación en redes internacionales para el intercambio de experiencias locales. Por su parte, los vínculos informales no cuentan con estructuras institucionales; asimismo, son de corta duración y no están sistematizados ni registrados en los sistemas de información de las administraciones públicas del orden territorial. Cabe señalar que unos (los formales) u otros (los pragmáticos) pueden generar importantes activos en determinado momento, siempre y cuando se adapten a los objetivos y las particularidades de la instancia que los instrumente.

Desde otra perspectiva, Díaz (2008) clasifica a las dinámicas de la CD a partir de un enfoque vertical y otro horizontal. Así, para este analista, la cooperación oficial descentralizada horizontal se refiere a aquella que realizan administraciones públicas subnacionales y otros agentes que interactúan en el mismo nivel, tanto de carácter gubernamental como no gubernamental. Por su parte, la de tipo vertical se lleva a cabo entre actores subnacionales con actores del Gobierno central o con organizaciones internacionales.

Sanahuja y Martínez (2009) proponen el análisis de modelos verticales y horizontales de CD desde otra perspectiva. En este sentido, las relaciones verticales pueden ser vistas desde el modelo tradicional y predominante caracterizado por prácticas asistencialistas Norte-Sur, con una marcada relación donante-receptor en la cual este último asume una actitud pasiva y dependiente que no evidencia claramente una relación entre socios que aporte a las capacidades de las partes.

A su vez, el modelo horizontal es un tipo de colaboración en el cual los actores asumen relaciones más estratégicas y recíprocas entre sí, en calidad de socios, en un esquema equitativo en el que los gobiernos subnacionales se convierten en sujetos activos de la cooperación. Esta práctica impulsa relaciones basadas en el mutuo interés, el intercambio de conocimientos y experiencias significativas de gestión para el apoyo a los procesos de descentralización y gobernabilidad local.

De esta manera, la lógica de la CD abre una oportunidad de relaciones de interrelación sin que sus promotores deban ceñirse de manera estricta a la totalidad de condiciones, instrumentos y modalidades de la cooperación oficial tradicional (aunque ello no signifique estar en contraposición de la misma, claro está). Con esto, las administraciones territoriales, haciendo uso de su autonomía, tienen diversas opciones para relacionarse con pares y otros actores internacionales mediante el establecimiento de convenios y hermanamientos, la creación y participación en redes, los intercambios, la asistencia técnica, etc.

De ahí que a la luz de dicho crisol de posibilidades, la CD pueda, en efecto, contribuir a favor de los procesos de desarrollo local, políticas públicas, planeación participativa y articulación multinivel. 
En palabras de Martínez y Sanahuja (2012):

...los gobiernos descentralizados están llamados a cumplir una función estratégica para la gobernanza global $[\ldots]$ y la cooperación descentralizada debería orientarse estratégicamente hacia el apoyo a la gobernabilidad local, hacia el fortalecimiento de la sociedad civil y las instituciones locales, o hacia el apoyo al diseño y la gestión de políticas públicas en el ámbito local.

\section{El CAso del departamento de Cundinamarca}

La Constitución Política de Colombia de 1991 establece que "Colombia es un Estado social de derecho, organizado en forma de República unitaria, descentralizada, con autonomía de sus entidades territoriales”. De la misma manera, establece que "son entidades territoriales los departamentos, los distritos, los municipios y los territorios indígenas", las cuales "gozan de autonomía para la gestión de sus intereses". Declara a los municipios como "entidades fundamentales de la división política administrativa del Estado", sobre los cuales recae la responsabilidad, ente otras cosas, de "ordenar el desarrollo de su territorio". Así, la división político-administrativa del país está organizada en 32 departamentos, 1.096 municipios y 5 distritos.

En Colombia, las relaciones de CD son promovidas por algunos gobiernos subnacionales como una manera de fortalecer sus procesos de internacionalización. Lo anterior mediante la firma de hermanamientos, la implementación de estrategias de marketing territorial, la vinculación en redes de gobier- nos locales a nivel internacional, la participación en programas para el desarrollo local promovidos por organismos internacionales, el intercambio de experiencias y buenas prácticas, la ejecución de proyectos y programas, entre otros.

Desde el ámbito municipal o departamental se evidencian algunas experiencias que sustentan esta afirmación. De acuerdo con el Informe Experiencias en Internacionalización Municipal en Colombia (2008), en algunas gobernaciones y ciudades capitales como Medellín, Bogotá, Bucaramanga, Cartagena, Manizales, Pereira, Pasto y Cali existen oficinas o espacios de gestión de asuntos internacionales, establecidos en la estructura administrativa de las citadas alcaldías. En la mayoría de estos casos la responsabilidad sobre los proyectos que tienen relación con el tema internacional recae en las oficinas de planeación, en el despacho del alcalde o en algún funcionario del nivel asesor. Es importante destacar la experiencia de Medellín, en el cual existe una institucionalidad más avanzada a través de la creación en el 2002 de una instancia propia: la Agencia de Cooperación Internacional e Inversión de Medellín y el Área Metropolitana, que tiene el objetivo de propiciar el desarrollo de la ciudad a través de la creación de relaciones con otros países y ciudades.

Bajo este mismo contexto, desde APCColombia se impulsan algunos mecanismos de acompańamiento y articulación con los niveles locales y departamentales para la cooperación internacional. Así por ejemplo, en el año 2003, la Dirección de Cooperación Internacional de Acción Social (hoy APc-Colombia) -intentando mejorar la institucionalidad de 
la cooperación internacional que se practica en el país- decidió conformar el Sistema $\mathrm{Na}$ cional de Cooperación Internacional. El fin de tal estrategia es mejorar la coordinación, el consenso y la articulación de todos los actores políticos, técnicos y reguladores de la cooperación internacional de Colombia. Lo anterior a efecto de vincular y articular de mejor manera las actividades que sobre esta materia se desarrollan en los órdenes local y departamental.

En esta tesitura, a partir del año 2003 se instaura la figura de los Comités de Coordinación y las Agendas sectoriales y territoriales como mecanismos de coordinación con los diversos actores del sistema. Así, la creación de los referidos Comités Departamentales de Cooperación representa una apuesta para reunir, coordinar, articular y establecer rutas de trabajo de cooperación con los diferentes actores del territorio, por ende fortaleciendo la institucionalidad de la cooperación en los departamentos y la interlocución con la APCColombia.

Sin embargo, a pesar de los avances en este sentido, al momento presente no se detectan estudios contundentes sobre la efectividad de estos mecanismos de articulación, y sobre la permanencia y sostenibilidad de estos procesos. Es destacable que APC-Colombia, a través de su Dirección de Cooperación Interinstitucional, incentiva un nuevo programa denominado "Cooperación Col-Col"; es decir, aquella cooperación entre entidades territoriales colombianas para promover el intercambio y la transferencia de conocimientos entre regiones, departamentos y municipios colombianos (APC-Colombia, 2016).
Ahora bien, a pesar de que existen las condiciones legales para promover la cooperación desde el ámbito territorial, sustentada en la Constitución Política, en Colombia la estructura del Estado tiende a concentrar este tema en el Gobierno central y en sus diferentes instancias. Esto se constata, por un lado, en la construcción de estrategias de cooperación en los últimos diez años con discreta participación de los actores departamentales y locales. Por el otro lado, en la insuficiente de capacidad institucional desde los territorios para planificar rutas de acción relacionadas con la CID.

La reducida capacidad institucional en materia de CID/CD de un gran porcentaje de municipios del país requiere de estrategias diferenciadas de fortalecimiento que incorporen los principios de concurrencia, complementariedad y subsidiariedad en un marco de unidad nacional y autonomía territorial (Departamento Nacional de Planeación, 2012).

\section{La institucionalidad de la cooperación internacional en el departamento de Cundinamarca}

Cundinamarca cuenta con 116 municipios agrupados en 15 provincias. Su PIB departamental anual en 2011 fue de $30.565 .000 \mathrm{mi}-$ llones de pesos, cuya participación porcentual en el piв Nacional fue de 4,9\% (Departamento Nacional de Planeación, 2013). El sector agropecuario lidera la estructura económica del departamento, seguido por la industria, los servicios y el comercio (Gobernación de Cundinamarca, 2014). El Índice de Desarrollo Humano en Cundinamarca es alto $(0,837)$ 
en comparación con otras regiones del país (PNUd, 2011).

Quizá por estas y otras razones, para las autoridades de este departamento, la CID no ha sido prioritaria. Sin embargo, es posible evidenciar municipios del departamento como Soacha, en donde la cooperación influye de forma considerable en la cofinanciación de su desarrollo, en especial por las condiciones humanitarias como consecuencia, entre otras cosas, de la alta recepción de desplazados ${ }^{1}$.

Para analizar la dinámica general de la cooperación internacional que se practica en años recientes en Cundinamarca, a continuación se examinan una serie de variables que desde el ámbito institucional, de gestión y articulación, pretenden mostrar los principales alcances y desafíos del departamento en este aspecto.

\section{a. El fortalecimiento institucional como eje transformador de las dinámicas de la cooperación internacional en el departamento de Cundinamarca}

Las iniciativas para fortalecer la institucionalidad de la cooperación internacional en el departamento de Cundinamarca se remontan a 19 años atrás. Sin embargo, tan solo desde los últimos ocho años, mediante la creación de la Secretaría de Cooperación y Enlace Institucional, en 2008 se comienza a evidenciar la apuesta y promoción de actividades de cooperación internacional más institucionalizadas y concretas, con proyección a largo plazo.

El proceso de construcción de un andamiaje institucional en el ámbito de la cooperación internacional inició en 1997, cuando la administración departamental crea la Oficina de Relaciones Nacionales e Internacionales al interior de la Gobernación. Su propósito fue el establecimiento de relaciones nacionales e internacionales que complementaran las acciones para el cumplimiento del plan de desarrollo ${ }^{2}$. Posteriormente, en septiembre de 1998, esta unidad administrativa adquirió el nombre de Oficina de Cooperación ${ }^{3}$, mientras que en el año 2008 la Gobernación decidió crear la Secretaría de Cooperación y Enlace Institucional $^{4}$.

A su vez, como un esfuerzo por coordinar la cooperación en los ámbitos nacional, departamental y local, en el ańo 2013 APCColombia creó el Comité Red Departamental de Cooperación de Cundinamarca. El Comité, cuya Secretaría Técnica le corresponde a la Secretaría de Cooperación, tiene como principales funciones:

\footnotetext{
A partir de la segunda mitad de la década de los noventa empiezan a llegar a Soacha la mayor parte de familias desplazadas (Neira, 2004).

2 Decreto 2457 del 7 de octubre de 1997.

3 Decreto 02184 del 30 de septiembre de 1998.

4 La Secretaría se creó con el Decreto 0258 de octubre de 2008, bajo la administración de Andrés González. La misión de esta Secretaría es la de promover y gestionar proyectos de cooperación nacional e internacional (Informe de gestión 2008-2011).
} 
...proveer la información necesaria para levantar la línea base de oferta y demanda, coordinar acciones conjuntas entre sus miembros, para poner en marcha y hacer seguimiento a la política de cooperación del departamento, identificar fuentes de cooperación y diseñar la estrategia de comunicación, divulgando además su gestión anual (art. 5, Decr. 0021 de 2013).

A continuación, en la tabla 2 , se relacionan los miembros del referido Comité, los cuales son definidos por la Gobernación, en el marco del Decreto reglamentario.

Sin embargo, llama la atención que desde entonces este Comité no ha avanzado de manera significativa en sus actividades fundacionales, lo cual demuestra su reducida capacidad para aglutinar a los actores que lo conforman y, por ende, actuar bajo una ruta estratégica que represente los intereses de los principales actores presentes en los procesos de desarrollo del departamento.

Para superar esta situación, en el año 2014 la Secretaría decidió reactivar este Comité como un espacio de diálogo, articulación y definición estratégica de mayor impacto en el ámbito de la CD. Quizás el avance más significativo tras ello, luego de esfuerzos inconclusos, fue la realización en ese mismo ańo del Taller para la Formulación del Plan Preparativo 2015 y la definición de la hoja de ruta operativa del Comité. Este ejercicio tuvo como propósito avanzar hacia una mejor y mayor comprensión territorial de los retos de las distintas regiones del departamento y sectores en materia de cooperación internacional para el 2015. Esta estrategia también

\section{TABLA 2. MIEMBROS DEL COMITÉ RED DEPARTAMENTAL DE COOPERACIÓN DE CUNDINAMARCA}

El gobernador de cundinarmarca, o su delegado.

El secretario de cooperación internacional y enlace institucional quien, a su vez, será el delegado de gabinete Departamental.

El secretario de planeación Departamental.

Un delegado del programa de las Naciones Unidas para el Departamento el Desarrollo el Colombia PNUD.

Un delegado de la asamblea Departamental.

Un delegado de la APC-COLOMBIA.

Un delegado de la Federación Colombiana de Municipios FMC.

Un delegado de la Pastoral Social.

Un delegado del Departamento Administrativo para la Prosperidad Social de las Presidencia de la República (DPS).

Un delegado de la Cámara de Comercio de Bogotá.

Un delegado de la Cámara de Comercio de Bogotá-Sede Zipaquirá.

Un delegado de la Cámara de Comercio de Bogotá- Sede Fusagasugá.

Un delegado de la Cámara de Comercio de Bogotá- Sede Cazucá (Soacha).

Un delegado de la Cámara de Comercio de Facatativá

Un delegado de la Cámara de Comercio de Girardot.

El director regional Sena Cundinamarca o su delegado.

Un delegado de la Corporación Universitaria Minuto de Dios (Uniminuto).

El gerente del Fondo de Desarrollo de Proyectos de Cundinamarca (FONDECUN), o su delegado.

El director del Instituto Departamental de Acción Comunal y Participación Ciudadana (IDACO), o su delegado.

Un delegado de cada bloque de provincias que para efectos de este decreto se han agrupado.

Fuente: elaboración propia, a partir del Decreto 0021 de 2013. 
contribuyó a la construcción del documento de "Hoja de ruta de la Cooperación para el Desarrollo Humano y la Construcción de Paz en Cundinamarca" (Gobernación de Cundinamarca, 2014).

Otro de los aspectos por considerar en el proceso a favor del fortalecimiento institucional de la CiD de Cundinamarca está relacionado con los planes de desarrollo del departamento. En este sentido, el Plan de Desarrollo "Cundinamarca - Calidad de Vida 2012-2016" establece la importancia del tema; en especial en el Objetivo 4: Fortalecimiento institucional para generar valor de lo público; Pilar 10: Fortalecimiento institucional y gobernabilidad; Programa: Modernización de la gestión; Componente estratégico: Cooperación y gestión estratégica para el desarrollo. En dicho apartado se plantea:

...diseñar una política pública en materia de cooperación internacional para orientar de manera integral la cooperación pública y privada que reciba y otorgue el departamento para el desarrollo efectivo del territorio, acercando con equidad la oferta de cooperación a la integridad del departamento, generando procesos de desarrollo prioritarios en los 35 municipios con mayor índice del NBI (Gobernación de Cundinamarca, 2012, p. 226).

Lo que evidencia este panorama es que, en efecto, el departamento de Cundinamarca cuenta con un marco normativo e institucional para regular y promover su cooperación internacional (inciso de los elementos que construyen institucionalidad de la CID indicado en la primera parte del artículo), que si bien se ha perfeccionado, engendra importantes elementos de oportunidad para regular con mejor capacidad dicha actividad.

No obstante, al indagar sobre los avances formales de este aspecto en sus 116 municipios, el panorama demuestra una capacidad y estructura institucional laxa. En general, en

TABLA 3. EXPERIENCIAS DE INSTITUCIONALIZACIÓN DE LA CID EN EL DEPARTAMENTO DE CUNDINAMARCA (2012-2014)

\begin{tabular}{|l|l|l|}
\hline \multicolumn{1}{|c|}{ Municipio } & \multicolumn{1}{|c|}{ Legislación } & \multicolumn{1}{c|}{ Espacio o modalidad para trabajar el tema de la CID } \\
\hline Facatativá & $\begin{array}{l}\text { Decreto No 288 de 05 de } \\
\text { diciembre de } 2012\end{array}$ & Oficina de Cooperación Internacional \\
\hline Cucunubá & NA & $\begin{array}{l}\text { Funcionario con la respondabilidad de gestionar cooperación inter- } \\
\text { nacional. }\end{array}$ \\
\hline Soacha & $\begin{array}{l}\text { Decreto ordenanza No } \\
00260 \text { de } 2008\end{array}$ & $\begin{array}{l}\text { Secretaría especial para soacha. } \\
\text { Funcionario con la respondabilidad de gestionar cooperación inter- } \\
\text { nacional. }\end{array}$ \\
\hline Fusagasugá & Decreto No 170 de 2013 & $\begin{array}{l}\text { Contratista que se encarga de estas labores. } \\
\text { En el 2013se creó nque el Comité de cooperación Nacional e inter- } \\
\text { nacional para el municipio. }\end{array}$ \\
\hline Puerto Salgar & NA & Desarrolla estas actividades desde I aSecretaría de Planeación \\
\hline
\end{tabular}

Fuente: elaboración propia. 
una importante cuantía de los municipios del departamento, la cooperación internacional no ha sido lo suficientemente relevante como para establecer una directriz definida que regule este aspecto mediante un espacio de coordinación y formalización vinculado a los procesos de planeación, gestión, seguimiento y rendición de cuentas. Esto explica, en parte, la reducida institucionalidad de la misma, cuyos rasgos más relevantes se señalan en la tabla 3.

Lo anterior permite aseverar que desde esta segunda perspectiva, el aspecto institucional de la cooperación internacional en el departamento a nivel de sus municipios es aún incipiente. Así lo evidenció también la Secretaría de Cooperación y Enlace Institucional en el informe de gestión con fecha de corte del 31 de diciembre de 2013, en el cual se menciona textualmente lo siguiente:

...existe una debilidad institucional -que debemos superar- para adelantar iniciativas y proyectos de naturaleza transectorial debido a la carencia de un grupo de expertos estructuradores de proyectos que, sin duda, se constituirían en una herramienta formidable para fortalecer la calidad de las propuestas que se formulan desde el nivel local y departamental. Una vez subsanada esta debilidad, el departamento estaría en capacidad de competir de manera más eficaz y articulada por recursos de cooperación técnica, financiera y transferencia de conocimiento. Es parte esencial de los retos que impone una inserción positiva en el plano internacional y, por ende, en los distintos procesos de globalización a los que asistimos en este siglo.

TABLA 4. ASPECTOS CONSIDERADOS EN LOS AVANCES DE INSTITUCIONALIZACIÓN EN EL DEPARTAMENTO DE CUNDINAMARCA (2008-2014)

\begin{tabular}{|l|l|}
\hline \multicolumn{1}{|c|}{ Aspecto } & Nivel \\
\hline Inclusión de los temas de cooperación internacional en el Plan de Desarrollo Departamental & Alto \\
\hline Inclusión de los temas de cooperación internacional en el Plan de Desarrollo Municipal & Incipiente \\
\hline Legistación relacionada con la industrialización y la formalización de la CID en el nivel departamental & Alto \\
\hline Legistación relacionada con la industrialización y la formalización de la CID en el nivel municipal & Incipiente \\
\hline Espacio de coordinación y gestión a nivel departamental & Alto \\
\hline Incidencia del espacio de coordinación y gestión a nivel departamental, en el nivel nacional y municipal & Incipiente \\
\hline Espacio de coordinación y gestión a nivel municipal & Incipiente \\
\hline Incidencia del espacio de coordinación y gestión a nivel departamental, en el nivel Nacional y Municipal & Incipiente \\
\hline Instrumentos a favor de la coordinación del nivel nacional, departamental y municipal & Medio \\
\hline $\begin{array}{l}\text { Instrumentos a favor de la coordinación (comité Red Departamental de Cooperación Internacional) } \\
\text { en la planeación estratégica de la cooperación }\end{array}$ & Incipiente \\
\hline $\begin{array}{l}\text { Materialización de definicion de objetivos, a través de una estrategia o una politica pública } \\
\text { departamental de CID }\end{array}$ & Medio \\
\hline
\end{tabular}

Fuente: elaboración propia. 
No obstante ello, en el año 2014 la Secretaría apostó a favor de la conformación de un espacio de capacitación para fortalecer en los 116 municipios del departamento los conocimientos en cooperación internacional. Así, esta instancia ofreció, con el apoyo de la Federación Colombiana de Municipios, un curso virtual en cooperación internacional para los gobiernos locales, en el cual participaron 43 personas de 10 municipios del departamento (Gobernación de Cundinamarca, 2014).

En síntesis, examinando el contexto institucional de la cooperación internacional en el departamento, desde el aspecto de legislación y de un espacio de gestión creado para tal fin, y su incidencia en los procesos de planeación y gestión, la tabla 4 es esclarecedora, en el sentido de la aún reducida institucionalidad de diversos elementos que la componen.

\section{b. La articulación, coordinación y rendición de cuentas de la CID en Cundinamarca}

En Colombia, como ocurre en otros países latinoamericanos, es recurrente observar reducidos niveles de articulación y coordinación de la cooperación internacional del nivel nacional con el departamental y de este con el nivel municipal. Si bien desde la instancia coordinadora del orden central (APC-Colombia) existen mecanismos como los Comités Departamentales de Cooperación, y las agendas sectoriales y territoriales para lograr tal articulación, los resultados son aún incipientes. Esto explica, entre otras cosas, la ausencia de información consolidada y el desconocimiento desde los tres niveles (nacional, departamental y municipal), de los proyectos y programas de cooperación internacional que con recursos técnicos y económicos se han ejecutado en el departamento.

De esta manera, la principal fuente de información sobre los proyectos de cooperación en el departamento es APC-Colombia (es decir, una instancia nacional y no local), la cual registra en un gran porcentaje los proyectos y programas promovidos y ejecutados desde el nivel central, dejando de lado lo ejecutado desde la administración departamental o municipal. En este escenario, en su mapa de cooperación, APC-Colombia registró entre el ańo 2012 y 2015 un total de 141 proyectos de cooperación internacional financiados mediante AOD y nuevas fuentes de cooperación exterior ${ }^{5}$. Estas cifras arrojan que en el departamento descrito hicieron presencia durante ese periodo aproximadamente 57 fuentes de cooperación internacional, tanto públicas como privadas. Entre los datos más representativos se encuentra que los actores bilaterales y multilaterales con mayor número de proyectos activos en este periodo en Cundinamarca fueron Japón, seguido de UNICEF, ACNUR, Unión Europea, Estados Unidos, el BID, entre los más importantes (figura 1).

\footnotetext{
5 De estos 141 proyectos, 58 son dirigidos directamente por el departamento. Los otros 83 hacen parte de proyectos del ámbito nacional que impactan a varios departamentos (APC-Colombia).
} 
De acuerdo con estos mismos datos registrados por APC-Colombia, resalta que "desarrollo social" y "derechos humanos" se constituyen en los dos temas con mayor impacto en la ejecución de estas iniciativas (APC-Colombia). En general, llama la atención que en estas iniciativas la responsabilidad de la Gobernación es casi nula, debido a que un gran porcentaje de estos proyectos fueron coordinados desde la administración central y los cooperantes (figura 2).

Ahora bien, cuando se contrastan estos datos con los que maneja la Gobernación, se observa una significativa divergencia entre unos y otros. En la actualidad no existe un sistema de información, registro y control consolidado que dé cuenta de los proyectos y convenios que han sido instrumentados en el periodo de tiempo estudiado. En el Informe de Gestión 2012-2015 de la Secretaría de Cooperación y Enlace Institucional, con ocasión del cambio de administración departamental, la Secretaría registró 12 proyectos de los cuales tan solo dos se encuentran en los registros de APC-Colombia. Guatemala, Corea, Canadá, Japón, Holanda, Dota (Costa Rica), Pichincha (Ecuador), gIz y Unión Europea son los socios de cooperación registrados a través de los 12 proyectos identificados (Gobernación de Cundinamarca, 2015a).

FIGURA 1. SOCIOS DE COOPERACIÓN INTERNACIONAL MÁS REPRESENTATIVOS EN CUNDINAMARCA, 2012-2015 (NÚMERO DE PROYECTOS ACTIVOS EN EL PERIODO)

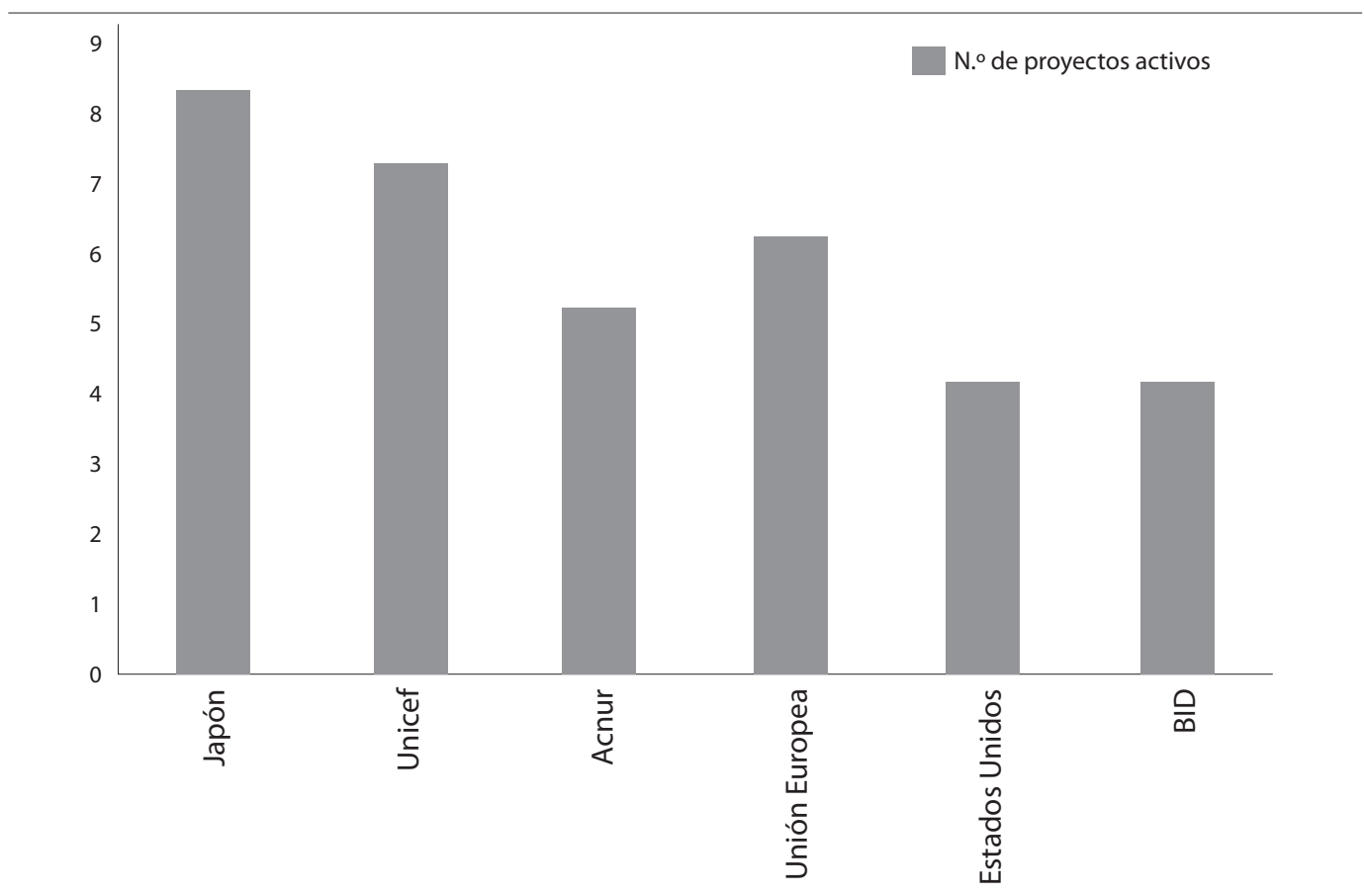


El panorama de descoordinación anteriormente descrito se evidencia aún más desde el nivel municipal. La ausencia de sistemas de control y de registro en los municipios que tienen alguna experiencia en el tema y la falta de memoria histórica entre una administración y otra, impiden identificar un panorama claro que sirva como base para avanzar hacia procesos con mayores niveles de planeación, gestión, evaluación y por ende institucionalización ${ }^{6}$.

Por tanto, se puede afirmar que la incipiente institucionalidad de la cooperación internacional en Cundinamarca, en especial en el nivel municipal, afecta a los procesos de programación, instrumentación, seguimiento, rendición de cuentas y -lo más importantemuy probablemente a los resultados de la colaboración realizada.

De la misma manera, es plausible que esta dinámica alimente el enfoque tradicional de relaciones que no sobrepasa los modelos tradicionales de tinte vertical y asistencialista, en razón de que, si no existe una adecuada institucionalidad de la $\mathrm{CD}$ realizada en el territorio,

FIGURA 2. CLASIFICACIÓN POR TEMA DE LOS PROYECTOS DE COOPERACIÓN INTERNACIONAL ACTIVOS ENTRE 2012 Y 2015

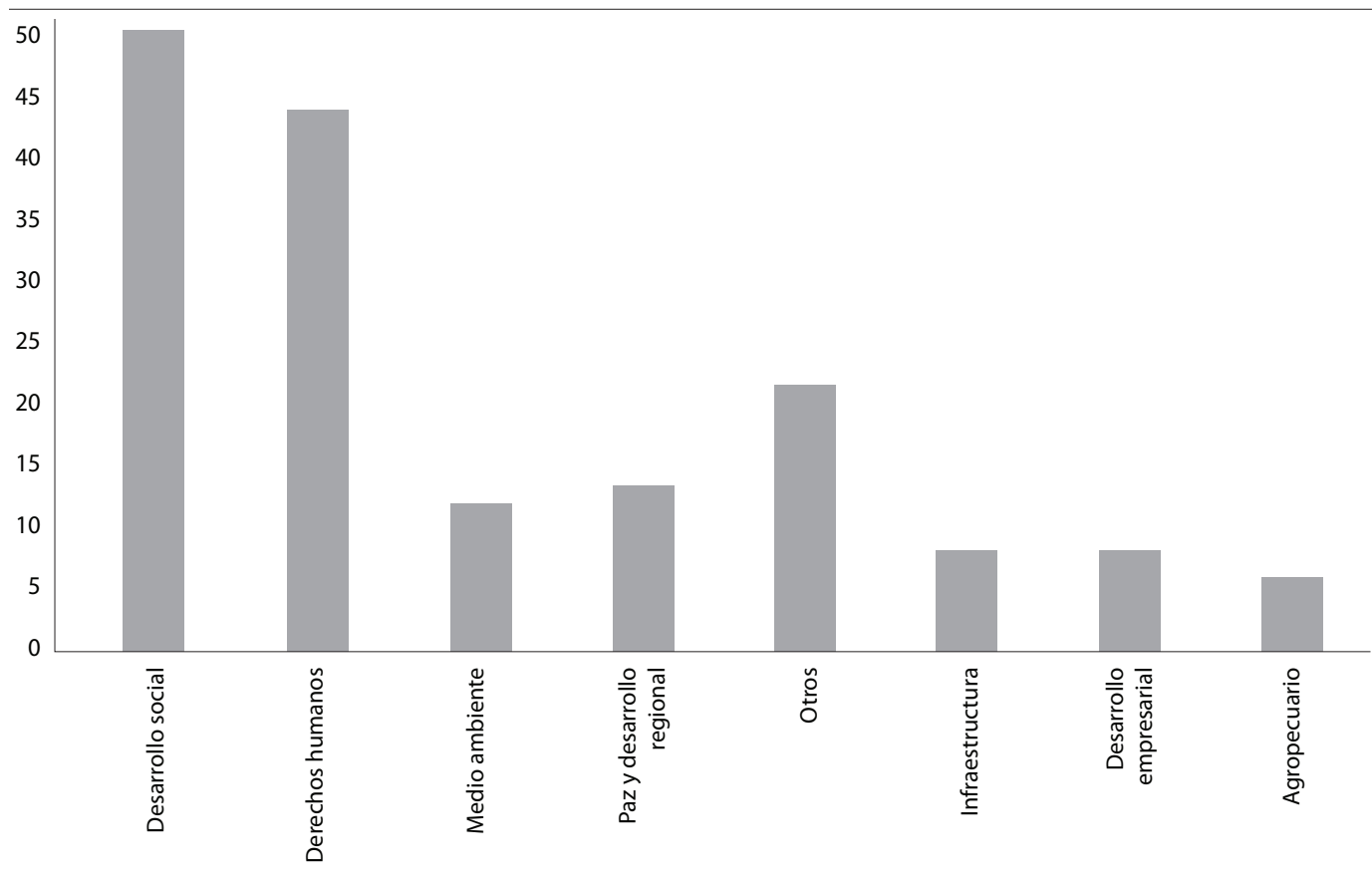

Fuente: elaboración propia a partir de los datos suministrados por APC-Colombia.

Esta conclusión hace parte del ejercicio realizado por la Universidad Jorge Tadeo Lozano y la Secretaría de Cooperación y Enlace Institucional. 
se dificulta el diseño de rutas estratégicas de programación, coordinación e intervención. En este escenario, cabe la posibilidad de que las acciones de cooperación sean decididas en el nivel central y desde el extranjero, afectando tras ello los procesos de apropiación y, a la postre, la eficacia de las acciones realizadas.

Para contrarrestar esta situación, desde el año 2013 la administración departamental de Cundinamarca (2012-2015) realizó esfuerzos en la construcción de una estrategia de cooperación internacional más integrada y funcional. Lo interesante y alentador del ejercicio fue el componente participativo y de desarrollo de capacidades que dicha administración quiso infundirle a dicho proceso. No obstante, el limitado equipo humano sumado a la discreta capacidad de respuesta del Comité Red Departamental de Cooperación, evidenció la debilidad institucional para definir e implementar objetivos claros en las actividades de cooperación internacional.

Por último, y como un aspecto fundamental de la institucionalización de la CID en esta Gobernación, la rendición de cuentas desde la administración departamental se realiza mediante los informes que la Secretaría de Cooperación y Enlace Institucional debe remitir a la Secretaría de Planeación Departamental. A su vez, esta última instancia los presenta a la Asamblea Departamental de Cundinamarca.

Así por ejemplo, en el informe a corte de 31 de diciembre de 2014, la Secretaría presentó los resultados de su gestión, relacionados principalmente con la firma de convenios, la gestión y ejecución de algunos proyectos con algunos cooperantes. Dicho compendio inclu- yó también datos sobre la capacitación a funcionarios de municipios, las becas otorgadas a algunos funcionarios de la Gobernación o de administraciones municipales, entre otros.

Más allá del informe de gestión que debe rendir la administración, llama la atención que no existe un sistema de evaluación sistemática que permita evidenciar los avances o retrocesos en la materia (tabla 5).

\section{REFLEXIONES FINALES}

Las transformaciones en la CID, junto al papel de los gobiernos locales, presentan una oportunidad para impulsar de manera continua procesos planificados que fortalezcan la institucionalización de esta modalidad de las relaciones internacionales.

A este respecto, los postulados institucionalistas de las Relaciones Internacionales en materia de cooperación internacional contribuyen a aclarar las pautas generales que explican aquellos procesos de conducción del comportamiento de aquellas entidades y gobernantes dedicados a realizar en sus respectivos espacios territoriales actividades en el ámbito de la colaboración externa. En este sentido, se deja constancia de que, desde esta perspectiva, las instituciones pretenden satisfacer necesidades colectivas, facilitando su cumplimiento mediante instrumentos programáticos y otros mecanismos operativos dedicados a aumentar la predictibilidad y eficacia de tales actividades.

En el caso de Colombia, la instauración de una agencia encargada de la cooperación internacional junto a la definición de tres estrategias y una hoja de ruta, dan cuenta del 
interés de institucionalizar de mejor manera los procesos de cooperación en el país. Sin embargo, como un oferente y receptor de cooperación, y a imagen y semejanza respecto a los otros países de la región, Colombia enfrenta el reto de promover las capacidades de los gobiernos locales y departamentales para una mayor planificación y articulación de la cooperación que responda a las realidades de los territorios.

Desde el nivel subnacional, aunque la institucionalización de la cooperación internacional es importante para consolidar procesos más planificados y acordes con el contexto de los territorios, y si bien se detectan avances en varios de sus componentes, su instrumentación depende en buena medida de la voluntad política del mandatario de turno; aspecto no analizado a profundidad por los institucionalistas.
Concretamente en cuanto a la institucionalización de la CD en Cundinamarca, tomando como referente algunos de los componentes a este respecto indicados en la primera sección de esta investigación, se señala lo siguiente:

a) Legislación ad hoc e institución permanente y estable que gestione la cooperación.

Como se vio en esta investigación, la administración departamental sí cuenta con un estatuto del orden jurídico para regular el ejercicio de la $C D$ que se realiza en dicha demarcación. A través de los Decretos 2457 de 1997, 02184 de 1998, 0258 de 2008, entre los más importantes, la Gobernación estableció la estructura operativa y de gestión de la cooperación internacional, que desembocó en la creación de la Secretaría de Cooperación y Enlace Institucional.

TABLA 5. ASPECTOS CONSIDERADOS EN LOS AVANCES EN LA GESTIÓN, COORDINACIÓN Y ARTICULACIÓN EN EL DEPARTAMENTO DE CUNDINAMARCA

\begin{tabular}{|l|l|}
\hline \multicolumn{1}{|c|}{ Aspecto } & Nivel \\
\hline Gestión de cooperación desde el nivel departamental & Medio \\
\hline Gestión de cooperación desde el nivel municipal & Incipiente \\
\hline $\begin{array}{l}\text { Sistemas de control y registro de la información desde el nivel } \\
\text { nacional }\end{array}$ & Medio \\
\hline $\begin{array}{l}\text { Sistemas de control y registro de la información desde el nivel } \\
\text { departamental }\end{array}$ & Incipiente \\
\hline $\begin{array}{l}\text { Sistemas de control y registro de la información desde el nivel } \\
\text { municipal }\end{array}$ & Nulo \\
\hline Articulación del nivel nacional con el departamental & Incipiente \\
\hline Articulación del nivel departamental con el nivel municipal & Incipiente \\
\hline Evaluación sistemática a nivel departamental & Incipiente \\
\hline
\end{tabular}

Fuente: elaboración propia. 
El establecimiento de un andamiaje jurídico de la cooperación internacional a través de una Secretaría permite garantizar los temas de dicha cooperación en la línea programática de la administración departamental. En este caso, para esta Gobernación el impulso de la cooperación internacional depende en gran medida del equipo técnico y de sus competencias para poner en marcha acciones que demuestren los avances de la proyección internacional del departamento.

b) Definición de objetivos explícitos, sectores, regiones y países prioritarios.

El departamento de Cundinamarca carece de este componente que se considera pieza nodal para una adecuada conducción del ejercicio de la CD. La principal consecuencia de lo anterior es que la $\mathrm{CD}$ en Cundinamarca no es de carácter programático (planificada bajo propósitos, temas y socios estratégicos), sino más bien de perfil reactivo, lo que limita posibilidades de que este ejercicio sea eficaz y adaptativo a las necesidades locales y nacionales. En este caso, la débil evidencia de los resultados del Comité Red Departamental de Cooperación permite afirmar que si bien existe un andamiaje jurídico e institucional "base", el departamento requiere no solo definir (como lo intentó hacer con la hoja de ruta finalizando la administración 2011-2015), sino implementar una clara estrategia de cooperación basada en las demandas y potencialidades de sus territorios, en correspondencia con los objetivos del Plan Departamental de Desarrollo 20162019.

c) Institución permanente y estable que gestione la cooperación.

Como se señaló en el inciso a, gracias a los decretos arriba citados la Gobernación creó la Secretaría de Cooperación y Enlace Institucional. Esto es significativo debido a que Cundinamarca es el único departamento del país que cuenta con un espacio de este tipo, lo que permitió, por ejemplo, que el tema fuera incluido de manera contundente en el Plan Departamental de Desarrollo 2012-2016, y que la Secretaría contara con recursos de inversión a partir del año 2013 (Gobernación de Cundinamarca, 2015b).

Sin embargo, tras contrastar los avances institucionales en los índices arriba citados, que en sí mismos son positivos, se advierte que no existe una clara relación entre estos con mayores niveles de gestión de cooperación internacional en el departamento. En el informe de gestión 2008-2011, la administración resalta dentro de sus resultados la ejecución de aproximadamente siete proyectos bajo una cooperación más focalizada con la cooperación técnica con Brasil, Costa Rica, Chile, Polonia, el Instituto Ideas México, la Fundación Bill Gates, entre otros. No existe información consolidada sobre recursos económicos gestionados desde la Gobernación para proyectos de desarrollo. 
Por su parte, en su informe de gestión 2012-2015 resalta la implementación de 12 proyectos de cooperación. Al respecto, llama la atención que en tal informe se destaca que Cundinamarca avanzó 14 puestos en el 2013 y 2014 a nivel nacional en la gestión de recursos de cooperación, pasando del puesto 21 al 7. Sin embargo, no parece evidente que esto tenga una relación directa con la gestión de la Gobernación (y sus 12 proyectos) sino quizás, con los reportes de la cooperación desde el nivel central representado por APC-Colombia.

En el caso de los niveles de institucionalidad de sus 116 municipios, el panorama parece diferente. Lo que se evidencia en estas entidades territoriales es una precaria formalización de espacios dirigidos a tal fin, en razón a que el interés en los temas internacionales depende de la voluntad política del Gobierno de turno y de la capacidad financiera y técnica para su adecuado uso.

d) Sistema de control y registro de los convenios, programas y proyectos de cooperación internacional.

En cuanto a este rubro es claro que en Cundinamarca, más allá de los avances registrados, el estado actual de identificación y registro de las acciones de CID dista de las características que un acervo actualizado y de vanguardia a este respecto debe tener. Los esfuerzos departamentales por consolidar un sistema de información de la cooperación en Cundinamarca, que incluya además lo que realiza APC-
Colombia, son casi nulos. Como se vio en este artículo, la demarcación sí cuenta con informes sobre las acciones de $\mathrm{CD}$ que se realizan; sin embargo, su propósito ha estado vinculado a la obligación de las administraciones territoriales de rendir cuentas ante las entidades competentes.

e) Recursos permanentes y contabilizados, destinados a la colaboración externa.

De acuerdo con el informe de gestión de la Secretaría (2012-2015) es posible destacar tres cambios sustanciales relacionados con la institucionalidad en este rubro: primero, a partir de 2013, la Secretaría pasó a tener recursos de inversión con un presupuesto de $\$ 1.980 .000 .000$ entre el año 2013 y 2015. Segundo, en el Plan de Desarrollo se incluyeron metas estratégicas relacionadas con la cooperación y la gestión para el desarrollo y el apoyo a la Red de cooperación para Cundinamarca. Por último, con el ánimo de reforzar las competencias del equipo humano, la administración 2012-2015 decidió aumentar la planta de funcionarios expertos, pasando de 3 a 4 directivos y de 1 a 3 asesores (2012 y 2015, respectivamente).

f) Personal capacitado y especializado en el ámbito de la CID.

La presente investigación confirma que el estatus de este aspecto es incipiente y por tanto requiere también de mayor relevancia y peso en el seno de dicho departamento. Así por ejemplo, y a pesar de demostrar un incremento en el equipo 
de toda la Secretaría, en el informe de gestión 2012-2015 se informa que esta oficina recibió el área de cooperación internacional con tres funcionarios y para diciembre de 2015, fue entregada con solo dos de ellos. Por tanto, se requiere ampliar la planta de funcionarios expertos para mejorar los procesos de planificación y gestión $y$, por tanto, de institucionalización.

g) Procesos de evaluación sistemática de los resultados de las actividades realizadas. A este respecto no existen evidencias que demuestren el seguimiento de resultados. Como se indicó previamente, los informes de gestión, que ofrecen información elemental sobre los proyectos y convenios realizados durante un periodo determinado, son la fuente más cercana de datos sobre la cooperación internacional que se impulsa desde la Gobernación de Cundinamarca. Ello indica que este elemento de institucionalidad en el departamento en cuestión es incipiente.

h) Mecanismos de rendición de cuentas con miras a -en caso necesario- reconducir decisiones y acciones a favor de mejores estándares de calidad.

En la administración departamental, los mecanismos de rendición de cuentas están limitados a los informes que deben ser entregados a la Secretaría de Planeación Departamental para su posterior presentación a la Asamblea Departamental. De la misma manera, estos informes no son públicos y, por ende, no es posible consultarlos de manera directa a través de la página web de la Gobernación. La principal implicación de ello es la carencia de los medios necesarios para detectar buenas prácticas a efecto de replicarlas o, en caso contrario, identificarlas y corregirlas.

i) Instrumentos a favor de la coordinación con respecto a los objetivos globales de desarrollo, las políticas nacionales y de otros territorios nacionales de cooperación internacional.

Desde la creación de la Secretaría de Cooperación y Enlace Institucional, la Gobernación mantiene un diálogo cercano con las instancias de cooperación del nivel central, hoy día representadas en APC-Colombia y la Cancillería. El propósito de este diálogo es no solo el del apoyo desde estas instancias nacionales en la gestión de cooperación, sino el de intentar alinear todas las acciones con las prioridades del Gobierno nacional y los compromisos internacionales que en materia de desarrollo y política exterior asume el país.

j) Todo ello en consonancia con los objetivos de desarrollo y de política exterior del país en cuestión.

En la misma dirección de lo mencionado en el inciso anterior, las acciones de cooperación de los gobiernos subnacionales deben ser acordes con las directrices de cooperación las que, a su vez, vienen alineadas con el plan nacional de desarrollo y la política exterior del país. 
Sin embargo, esto merece un estudio de mayor profundidad que permita medir, desde otras perspectivas, el nivel de alienación y diálogo político de las acciones del departamento de Cundinamarca y las prioridades del Gobierno nacional.

Dicho lo anterior, tal y como este artículo argumenta en su contenido, más allá de los avances conseguidos en años recientes, el departamento de Cundinamarca requiere priorizar la coordinación al interior de la Gobernación. Ello en especial mediante mayores recursos técnicos, humanos y financieros que complementen los logros alcanzados a favor de mayores niveles de articulación y trabajo en red con las demás secretarías de despacho, con los 116 municipios del departamento y demás actores públicos y privados.

Adicionalmente, el referido fortalecimiento institucional requiere de una visión estratégica desde el nivel municipal y departamental en la cual es fundamental definir una ruta de acción soportada en las demandas del territorio y sus potencialidades que pueden convertirse en oferta de cooperación. Avanzar en ese propósito permitirá sobrepasar el modelo vertical y asistencialista Norte-Sur para promover un modelo horizontal de relaciones entre socios y actores del desarrollo.

Por otro lado, los mecanismos de información entre APC-Colombia y las instancias departamentales y municipales encargadas de los temas de cooperación internacional, se convierten en medios necesarios para fortalecer la institucionalidad y promover la rendición de cuentas, la articulación y la coordinación.
Es plausible que dicho esquema dé paso hacia mejores índices de coordinación, alineación y desarrollo de acciones de mayor impacto, que eviten la duplicidad de proyectos e incentiven la participación de la sociedad civil. En este sentido, dentro de este proceso de mejoramiento de la institucionalización es deseable fortalecer las capacidades y las nuevas modalidades de cooperación internacional, como la css, la triangular, la cooperación en red y las alianzas intermunicipales. De igual forma, el liderazgo por parte de APC-Colombia como ente regulador de alcance nacional de la CD en este país también es pieza clave en este proceso de perfeccionamiento institucional de la colaboración en y desde los territorios. Finalmente, una mejor institucionalización de las políticas y los procesos de CD requiere indudablemente de la voluntad política por parte de los gobernantes locales. Esta precondición -cuyo estudio no es valorado por los teóricos institucionalistas- es fundamental para mejorar y mantener procesos en pro de una institucionalidad que de manera gradual pero permanente perfeccione las acciones y los resultados de la CID en lo general y de la $\mathrm{CD}$ en lo particular.

En definitiva, y a manera de corolario, esta investigación sostiene que en aras de mejorar la institucionalidad de la CD es necesario en primera instancia asegurar la voluntad política por parte de los tomadores de decisiones en pro de dicho propósito. Lo anterior es relevante, dado que los municipios del departamento en cuestión no cuentan con suficientes capacidades en cooperación, diseño y formulación de proyectos. Para ello, parece necesario implementar también una estrate- 
gia de identificación de capacidades tanto al interior de la administración departamental como de los entes territoriales ${ }^{7}$.

De esta forma será posible continuar avanzando hacia la conformación de una política pública de cooperación internacional de perfil descentralizado o nacional para el fomento de mejores cánones de desarrollo a favor de la población.

\section{REFERENCIAS}

Alonso, J. A. (2007). ¿Debe darse ayuda a los paises de renta media? Instituto Complutense de Estudios Internacionales. Madrid: Editorial Complutense. Recuperado de https://www.ucm.es/data/cont/ docs/430-2013-10-27-ICEI_PAPER_oI.pdf

APC-Colombia (2013). Mapa de cooperación internacional. Recuperado de http://190.248.17.195:8000/ mapacooperacion/apcNew2.3/

APC-Colombia (2013). Manual de acceso a la cooperación internacional. Recuperado de http://www.apccolombia.gov.co/?idcategoria=1469\#\&panel1-1

APC-Colombia (2016). Informe de gestión APC-Colombia 2015. Recuperado de https://www.apccolombia. gov.co/recursos_user//Documentos/Informe-deGestion-APC-Colombia-2015.pdf

Ayllón, B. y Costa, I. (2010). La cooperación Sur-Sur de Brasil: proyección solidaria y política exterior. En Ayllón, B. y Surasky, J. (coords). La cooperación Sur-Sur en Latinoamérica: utopia y realidad (pp. 69-101). Madrid: La Catarata.
Ayllón, B. (2016). ¿Latinoamérica dividida? Procesos de integración y cooperación Sur-Sur. Quito: Instituto de Altos Estudios Nacionales - Clacso.

Constitución Política de Colombia (1991).

Cortes, J. L. y Grandas, D. (2008). Informe Experiencias en internacionalización municipal en Colombia. Bogotá: Federación Colombiana de Municipios y Universidad de Bogotá Jorge Tadeo Lozano.

Cremer, G. (2008). Corruption y development aid. Confronting the challenges. London: Lynne Rienner Publishers.

Decreto 0021 (2013). Por el cual se crea el Comité Red Departamental de Cooperación de Cundinamarca. Diario Oficial 15062.

Del Huerto, M. (2005). Análisis de la cooperación descentralizada local. Aportes para la construcción de un marco de referencia conceptual en el espacio de las relaciones Unión Europea-América Latina. En Anuario de la cooperación descentralizada (pp. 44-63). Barcelona: Observatorio de Cooperación Descentralizada.

Departamento Nacional de Planeación (2012). Evaluación del desempeño integral de los municipios 2013. Informe de resultados. Recuperado de http:// colaboracion.dnp.gov.co/cdt/desarrollo\%20territorial/docuemnto $\% 20$ desempe $\% \mathrm{C} 3 \% \mathrm{~B} 1 \mathrm{o} \% 20$ integral\%202013.pdf

Departamento Nacional de Planeación (2013). Regionalización del presupuesto de inversión 2014. Recuperado de https://www.dnp.gov.co/LinkClick. aspx?fileticket=EKjBJzdlciE\%3D\&tabid=1544

Esta fue una de las conclusiones del diagnóstico de la cooperación internacional en Cundinamarca, en un ejercicio realizado por la Universidad Jorge Tadeo Lozano y la Secretaría de Cooperación y Enlace Institucional de la administración, 2012-2015. 
Díaz, A. L. (2008). La COD, cambio y resistencia en las relaciones internacionales contemporáneas. Madrid: Catarata.

Gobernación de Cundinamarca (1997). Decreto 2457 del 7 de octubre por el cual se crea la Oficina de Relaciones Nacionales e Internacionales.

Gobernación de Cundinamarca (1998). Decreto 02184 del 30 de septiembre por el cual se modifica la Oficina de Relaciones Nacionales e Internacionales a Oficina de Cooperación.

Gobernación de Cundinamarca (2012). Plan de desarrollo de Cundinamarca. Recuperado de http:// www1.cundinamarca.gov.co/gobernacion/LinkClick.aspx?fileticket=xx7Mq9Onb8w\%3d\&tab $\mathrm{id}=86 \& \mathrm{mid}=1030 \&$ language $=$ es - ES

Gobernación de Cundinamarca (2013). Informe de Gestión 2014. Secretaria de Cooperación y Enlace Institucional. Bogotá: Gobernación.

Gobernación de Cundinamarca (2014). Informe de Gestión. Secretaría de Cooperación y Enlace Institucional. Bogotá: Gobernación.

Gobernación de Cundinamarca (2015a). Informe de Gestión 2012-2015, Secretaria de Cooperación y Enlace Institucional. Bogotá: Gobernación.

Gobernación de Cundinamarca (2015b). Informe de Gestión Cundinamarca calidad de vida 2012-2015. Recuperado de http://www.cundinamarca.gov. co/wps/wcm/connect/4ed17090-b6b9-422c9d1b-7278861bcbd8/Inf++Gestion+2012$2015++$ pdf.pdf?MOD $=$ AJPERES

Gutiérrez, A. (2006). Análisis de la cooperación descentralizada local. Una aproximación a las relaciones de cooperación descentralizada entre la UE y América Latina. Observatorio de la cooperación descentralizada, Unión Europea-América Latina. Recuperado de http://observ-ocd.org/sites/observ-ocd.org/ files/publicacion/docs/235_29_2.pdf
Jackson, R. y Sorensen, G. (2010). Introduction to International Relations. Theories and Approaches. Oxford: Oxford University Press.

Karns, M. y Mingts, K. (2010). International Organizations. The Politics and Processes of Global Governance. London: Lynne Rienner Publishers.

Kay, S. (2006). Neoliberalism: Institutions at war. En Sterling-Folker, J. Making Sense of International Relations Theory. London: Lynne Rienner Publishers.

Martínez, I. y Sanahuja, J. A. (2009). La agenda internacional de eficacia de la ayuda y la cooperación descentralizada en España. Madrid: Fundación Carolina.

Martínez, I. y Sanahuja, J. A. (2012). Eficacia de la ayuda y división del trabajo: retos para la cooperación descentralizada española. Madrid: Ceipaz.

Neira, P. (2004). Desplazamiento forzado en Soacha: ¿se recuperan los desplazados del choque inicial? Bogotá: Universidad de los Andes.

OECD (2013). Detailed aid stadistics: Official and private flows, oECD International Development Statistics (database). Recuperado de http://www.oecd-ilibrary.org/development/development-key-tablesfrom-oecd_20743866

OECD (2016). Development aid at a glance, statistics by region: América. Recuperado de https://www. oecd.org/dac/stats/documentupload/3\%20America $\% 20-\% 20$ Development $\% 20$ Aid $\% 20$ at $\% 20$ a\%20Glance\%202016.pdf

Olivié, I. y Domínguez, R. (2013). Elementos para el posicionamiento de España en la construcción de la agenda de desarrollo global. Madrid: Real Instituto Elcano de Estudios Internacionales y Estratégicos.

PNUd (2011). Informe Nacional de Desarrollo Humano 2011. Colombia rural. Razones para la esperanza. Recuperado de http://hdr.undp.org/sites/default/ files/nhdr_colombia_2011_es_low.pdf 
Prado, J. P. (2011). La gobernabilidad de la cooperación internacional para el desarrollo de México. Revista Española de Desarrollo y Cooperación. Madrid: Instituto Universitario de Desarrollo y Cooperación-Universidad Complutense de Madrid.

Prado, J. P. (2013). La cooperación internacional para el desarrollo en la política exterior del presidente Felipe Calderón. Foro Internacional, El Colegio de México, LIII, 213-214.

Prado, J. P. (2014). El liberalismo institucional. En Schiavón, J. et al. Teorías de Relaciones Internacionales en el siglo Xxi. México: Interpretaciones críticas desde México, Benemérita Universidad Autónoma de Puebla.

Rojas, D. (2007). ¿ Hacia dónde va la política exterior de Colombia? Apuntes para el debate. Revista Colombia Internacional Universidad de los Andes, 65, 14-37. Recuperado de http://colombiainternacional.uniandes.edu.co/view.php/90/index. php?id $=90$

Sterling-Folker, J. (2013). Liberal Approaches. En Making sense of international relations theory. London: Lynne Rienner Publishers. 